\title{
Can Patients and Psychiatrists be Friends?
}

A Pragmatist Viewpoint

David H. Brendel

\section{OpenEdition}

\section{Journals}

Electronic version

URL: http://journals.openedition.org/ejpap/835

DOI: 10.4000/ejpap.835

ISSN: 2036-4091

\section{Publisher}

Associazione Pragma

\section{Electronic reference}

David H. Brendel, «Can Patients and Psychiatrists be Friends? », European Journal of Pragmatism and American Philosophy [Online], III-2 | 2011, Online since 29 December 2011, connection on 01 May 2019. URL : http://journals.openedition.org/ejpap/835 ; DOI : 10.4000/ejpap.835

This text was automatically generated on 1 May 2019.

\section{c) (†) $९$}

Author retains copyright and grants the European Journal of Pragmatism and American Philosophy right of first publication with the work simultaneously licensed under a Creative Commons AttributionNonCommercial-NoDerivatives 4.0 International License. 


\title{
Can Patients and Psychiatrists be Friends?
}

\author{
A Pragmatist Viewpoint
}

David H. Brendel

\section{The Dilemma of Patient/Psychiatrist Friendship}

1 The patient/psychiatrist relationship is one of the most complex in contemporary society. Individuals with an incredibly broad range of emotional and interpersonal problems come to psychiatrists expecting rigorous diagnosis in accordance with current medical knowledge, support and empathic understanding, and the highest level of professionalism (including respect, discretion, privacy, and confidentiality). Psychiatrists must use their scientific understanding of the brain, their psychological understanding of the human mind and interpersonal relationships, and their gut-level intuitions about people to guide them in asking the right questions, establishing accurate diagnoses, and prescribing the right course of treatment (including psychotropic medications, psychotherapies, and other modalities). In order to accomplish these goals, they must gather an enormous amount of personal information about the patient and establish a therapeutic alliance that is based on trust and fidelity to the professional role. In the very best situations, and especially in long-term treatment, a mutual bond between the two individuals gets forged. That bond is marked by mutual respect, trust, and emotional resonance.

2 In some cases, as the bond solidifies over time and the patient gets well, the professional relationship can begin to look and feel like a friendship. I will soon define in some more detail what I mean by friendship in this context. But for the moment, I will articulate what I take to be a core tension and dilemma in psychiatric practice today. In ideal treatment situations, the patient and the psychiatrist develop a deep interpersonal respect, trust, empathy, and basic liking toward one another. The treatment has worked and the patient's condition has stabilized. In the course of this development of a therapeutic alliance over months or years, the two parties have come to feel warmly, 
even lovingly, toward each other. For the moment, we can exclude situations in which there is an erotic or sexualized transference or countertransference in play, and just focus on the problem that begins to arise when a genuine friendship is established. Patient and psychiatrist have both played their societally defined roles as well as one can imagine. But over the course of time, mutual wishes for a personal relationship have understandably, and ineluctably, come to the fore. Now the two have a real problem.

One of the great ethics issues in 20th and 21st century psychiatry has revolved around the issue of professional "boundaries," which I put in quotation marks in order to problematize the concept and because the discussion of patient/doctor boundaries has become so arid and rigidified in recent years. The conventional wisdom is that a "boundary crossing" occurs when a psychiatrist steps outside the usual professional role in such a way that does not harm the patient, while a "boundary violation" involves an action outside the usual professional role but in which the patient is harmed or put at serious risk of being harmed (Gabbard \& Nadelson 1995). Some behaviors - such as having a sexual relationship or entering a financial relationship with a current patient - are considered absolutely unethical and are subject to professional discipline, such as revocation of a license to practice medicine, and to malpractice actions. There is more debate about whether psychiatrists can ever ethically enter a romantic or a financial relationship with a former patient, but even here there is a trend toward tighter rules and regulations. For example, until a few years ago, the American Psychiatric Association policies stated that a psychiatrist member of the Association needed to wait at least two years before dating a former patient. The more recently adopted policy essentially states "once a patient, always a patient" - and prohibits a member of the APA from ever dating a former patient.

Much less has been said about friendship with current or former patients in written bylaws of professional associations or in state regulations governing the practice of medicine, but friendships between psychiatrists and patients have generally been frowned upon - largely because they may create a "slippery slope" toward sexual, financial, or other harmful boundary violations. Some hospitals have written policies that prohibit psychiatrists from ever socializing with current or former patients, and subject any psychiatrist who does so to the possibility of disciplinary action, up to and including termination from the hospital staff. These hospitals, in many cases, tacitly exempt certain social interactions between patients and doctors, such as those that occur at hospital fundraisers. It is ironic that the attendees at such social functions often are members of a wealthy and exclusive group, often called the "Friends of Hospital X." However, if not endorsed by the hospital, the psychiatrist, in establishing a personal friendship with a current or former patient, puts himself or herself at significant risk of termination of employment, professional embarrassment, and possibly even loss of a license to practice medicine.

The problem is that, in many psychiatric treatments that have gone well, patients and their families are grateful to the physician and seek the kind of personal attachment that, in most interpersonal relationships, are harmless and, in fact, highly desirable. Psychiatrists routinely receive invitations to attend patients' weddings, graduations, milestone birthday parties, and countless other such events. They are frequently presented with gifts, sometimes ones that are handmade especially for the psychiatrist (perhaps a sweater, or piece or art), as human expressions of gratitude and friendship. In some cases, the psychiatrist can find a way to decline the invitation or the gift without 
creating hurt feelings, distancing the patient emotionally, harming the therapeutic alliance, or placing the treatment at risk. But in many cases, that simply isn't possible. Declining or rejecting a gift or an invitation may do more harm than good. In fact, accepting the invitation or gift might deepen the emotional bond between the two parties and lead to a stronger relationship. The psychiatrist, in some such situations, faces a troubling dilemma. Should he or she err on the side of fidelity to the traditional professional role, thereby shielding against a possible "slippery slope" toward a boundary violation - but putting the warm and human bond at risk? Or should he or she take a risk by stepping outside the conventions, thereby deepening the human connection - but creating the risk that a real or perceived "boundary violation" will later harm the patient or threaten the psychiatrist's career? This kind of scenario presents one of the core dilemmas that practicing psychiatrists currently face. Working it through can be enhanced by an understanding of the philosophy of friendship and how it might apply to contemporary psychiatric practice.

\section{Philosophy of Friendship and Psychiatry}

6 The philosophy of friendship has a long and storied history in the West. In the Nicomachean Ethics, Aristotle grappled with what defines the essence of friendship and made some key points that remain relevant to the current debate in philosophy and psychiatry. Aristotle talks about friendships that involve an "inequality between the parties" (e.g., between father and son) and which, in the best cases, are nonetheless "abiding and excellent" (Aristotle 1941: 1065-6). When each party contributes to the relationship in proportion to what each has to offer, then "in a sense arises equality, which is certainly held to be characteristic of friendship" (Aristotle 1941: 1066). The son becomes a man, the patient gets well - and the once lopsided relationship moves onto a more equal footing. At that point, Aristotle's commentary on the mutual love and friendship that may develop between similar individuals comes into play. Aristotle here talks about 3 distinct kinds of friendship. The first 2, which are far less desirable than the third, are rooted in pleasure and utility; when pleasure and usefulness dissolve for one or both parties in the dyad, so too does the friendship. The "perfect friendship," on the other hand, for Aristotle is "the friendship of men who are good, and alike in virtue" (Aristotle 1941: 1061). There is no well-considered reason that such friendship cannot develop between an emotionally attuned psychiatrist and a healthy patient over the course of a long term treatment. Such a development is a rare event, certainly, perhaps even a black swan; but it may constitute the very best outcome of a psychiatric treatment rather than be something we feared, regulate against, or punish. Aristotle writes:

It is natural that such friendships should be infrequent; for such men are rare. Further, such friendship requires time and familiarity; as the proverb says, men cannot know each other till they have 'eaten salt together'; nor can they admit each other to friendship or be friends till each has been found lovable and been trusted by each. Those who quickly show the marks of friendship to each other wish to be friends, but are not friends unless they both are lovable and know the fact; for a wish for friendship may arise quickly, but friendship does not. (Aristotle 1941: 1061-2)

7 These points Aristotle makes about friendship could be equally applied to our considerations of the patient/psychiatrist relationship. The contemporary psychotherapy and psychoanalytic literatures are rife with references to the importance of the 
Aristotelian ideal of a long-term emotional bond and trust between the two parties, even in light of the obvious differences between them (e.g., the fact that the patient pays the therapist). The same can be said of more recent philosophy of friendship. The great pragmatist philosopher and educator John Dewey, in his wonderful book Art as Experience, grapples with the question of how one culture absorbs the artistic contributions of a preceding culture. In his explanation of this creative and imaginative sociocultural process, he makes a comparison to the growth of a deep friendship. His description could be equally true of the therapeutic relationship in psychiatry:

The problem in question is not unlike that we daily undergo in the effort to understand another person with whom we habitually associate. All friendship is a solution of the problem. Friendship and intimate affection are not the result of information about another person even though knowledge may further their formation. But it does so only as it becomes an integral part of sympathy through the imagination. It is when the desires and aims, the interests and modes of response of another become an expansion of our own being that we understand him. We learn to see with his eyes, hear with his ears, and their results give true instruction, for they are built into our own structure. (Dewey 1934: 350)

And in a recent treatment of the philosophy of friendship by philosopher Bennett Helm (Love, Friendship, \& the Self: Intimacy, Identification, \& the Social Nature of Persons), we find an account of love as intimate identification between two people, and an analysis of how interpersonal emotional connectedness is essential to human flourishing, autonomy, and self-determination. Helm develops a notion of "plural agency" in which human choice and expression are constituted within relationships, the most powerful of those being loving friendships (Helm 2010: 266-7). Once again, we could easily substitute "therapeutic alliance" for "friendship" throughout most of this work and have an extremely compelling account of what psychiatric treatment looks like at its very best.

All of which leads me back to considering how this view of human connectedness collides with the conventional view of "boundaries," and the professional regulations around them, in the patient/psychiatrist relationship. In their training, psychiatrists are far more likely to read the work of psychiatrist Glen Gabbard than they are to read Aristotle, Dewey, or Helm. Gabbard \& Nadelson (1995), representing the mainstream of the contemporary psychiatric and psychoanalytic professions, draws on Freudian concepts of transference and countertransference to describe the emotional connectedness between patient and doctor. Rooted in the Freudian tradition, he tends to see the most powerful emotional forces in the therapeutic dyad to be repetitions of problematic, traumatic early experiences. In other words, when a patient has a strong emotional or erotic reaction to a therapist, this is to be understood as "transference" - a replication of a problematic relationship in early childhood, which needs to be interpreted by the therapist and "worked through" in the course of treatment. Similarly, the psychiatrist's deep and powerful emotional or erotic reaction to a patient is to be understood as "countertransference" - a repetition of a complex relationship in the therapist's early life. In this mainline view, countertransference needs to be identified, managed, and never acted out. When psychiatrists do act out countertransference, they may put the patient at risk of harm or exploitation.

This kind of power dynamic in the patient/psychiatrist interaction has been thoughtfully analyzed by Alan Wertheimer in his book entitled Exploitation (1999). Real world experience has indeed taught us that a small but troublesome minority of psychiatrists do sociopathically exploit vulnerable patients for their own sexual or other selfish 
gratification. However, most countertransference reactions (the vast majority, in fact) are not driven or accompanied by exploitative dynamics - they are more likely to be driven by the affiliative, loving dynamics which Aristotle, Dewey, and Helm discuss. Those are not the writers that most psychiatrists read these days, however. Psychiatrists are more likely to question the possibly pathologic nature of their countertransference feelings than to accept them and elaborate upon them in order to forge a closer human connection with the patient. This is the other, and certainly more common, form of "boundary violation" in contemporary psychiatry - the psychiatrist avoids or retreats from emotional connectedness with the patient for fear of the slippery slope, exploitation of the other, and professional ruin for oneself. Although they rarely read hard-core philosophy, psychiatrists end up adhering to principles articulated by philosopher Michael Hardimon, who authored a well-known article entitled "Role Obligations" in the Journal of Philosophy (1994). Hardimon argues that professional morality and ethics are rooted more in institutional and fiduciary roles than in character virtues of the human individual playing those roles.

11 Hardimon helps us to see the importance of identifying and considering the moral norms that govern professional roles. However, a primarily rationalistic philosophy of professional role obligations does not prevent or regulate against the development of mutual feelings or the growth of a patient/psychiatrist friendship. We also must note that psychoanalytic theory, with its emphasis on transference/countertransference dynamics, is considered outdated and largely discredited, even within the field of psychiatry itself (the field now is much more focused on cognitive neuroscience than on psychoanalytic or psychodynamic theory). And the professional regulations at the levels of hospitals, clinics, physician associations, and state licensing boards may be overly rigid, guided by out-of-date theories like classical psychoanalysis, and focused on preventing worst-case scenarios rather than developing guidelines for more ordinary situations. The openended views of friendship, such as those of Aristotle, Dewey, and Helm, appear to have little place in contemporary psychiatric thinking or practice.

So how might we approach the question I pose in the title of this paper? Can patients and psychiatrists be friends? We might approach it by first asking whether we wish to formulate a modern or postmodern response. Like most contemporary philosophers, I reject out of hand any absolutist answer to this or related questions - there is no metaphysical truth about the world, or any norm independent of our own human experience, that will help us here. But the modern versus post-modern question might be usefully posed as follows: can the "communicative rationality" of a philosopher like Jürgen Habermas help us to an answer? Habermas (1998) has great faith in reason and discourse. Under ideal conditions for discourse about our question (either in general, or as applies to the friendship between a particular patient and psychiatrist), Habermas might argue that we can find a rational, true answer that grows out of our discourse and normative practices.

But reason is in more trouble than Habermas appreciates. Discourse about this question on patient/psychiatrist friendship never really gets off ground because of fear of embarrassment and professional ruin. Psychiatrists are scared to talk about the real nature of their relationships with patients for fear that they will be reported to authorities, have their jobs and licenses revoked, or face media scrutiny about questionable professional practice. And so what we are really dealing with is a frightening set of postmodern dynamics around our central question. Michel Foucault's work (1965) 
may tell us more than Habermas's about the power dynamics in play here. The answer to our question, it seems, is driven more by power politics and historical contingencies than by rational discourse aimed at defining ethically sound norms.

\section{Clinical Pragmatism and Patient/Psychiatrist Friendship}

14 I am neither as sanguine as Habermas, nor as cynical as Foucault, about how to formulate an answer to the question of whether patients and psychiatrists can be friends. Neither modernist nor postmodernist forms of reasoning provide a clear and complete answer. In much of philosophical thinking and medical ethics, these two modes of reasoning stand in a dialectical relationship to each other anyway. None of us can be full-fledged modernists or post-modernists, especially when grappling with philosophical and ethical questions that have such powerful and profound real-world effects and manifestations. Here is where philosophical pragmatism can do some important conceptual and practical work for us. Clinical pragmatism provides a via media between the extremes of modernism and postmodernism. Of course, there are many different forms of philosophical pragmatism available on the contemporary scene, so I need to describe something about my own, distinguish it from other well-known versions, and show how it provides a useful lens through which we can look at the problem of whether patients and psychiatrists can be friends.

My own version of philosophical and clinical pragmatism aims to work dialectically between science and humanism, modernism and postmodernism, regulation and individual freedom. It sees each of these polar positions as critical, but inadequate, moments in a dynamic and integrative process. For example, with regard to philosophic "truth," the version of pragmatism I advocate neither embraces wholeheartedly Habermas's modernist ideal of a truth rooted in communicative rationality and discourse, nor Richard Rorty's postmodernist approach (1982) which is defined by what is most expedient or imposed by those in power. With regard to the question of whether patients and psychiatrists can be friends, there is little likelihood that rational discourse will lead to a rational and consensual norm, in part because the climate of shame and fear about this subject shut down the open and honest discourse which Habermas's theory requires. On the other hand, it would be nihilistic to swing the pendulum to Rorty's extreme and accept that there are no guiding principles in play here other than expediency and capricious decisions by those in power. In other words, in the current environment, rational discourse cannot lead to a well thought out position on patient/psychiatrist friendship in general or on the acceptability of a particular patient/psychiatrist friendship, as the conversation never gets off the ground. On the other hand, willy-nilly, local decisions by those in power (such as state medical boards or hospital administrators) about the general or the particular question are unlikely to be informed by a nuanced philosophy of friendship or a careful consideration of the nature of a particular friendship between two people.

The pragmatist begins from the position that this tension exists and is never fully resolvable. As such, the psychiatrist must acknowledge and learn to live and practice within an ambiguous space in which there are equally strong pulls toward unfettered human friendship and toward professional fidelity and regulation. In order to understand 
the nuances of this situation and successfully negotiate its challenge, the psychiatrist needs to engage in philosophical and moral self-reflection, personal psychotherapy, consultation with colleagues and mentors within confidential and privileged relationships, and possibly even engagement of attorneys, ethicists, and risk management specialists. Even for psychiatrists who make a conscious choice to avoid even approaching an Aristotelian form of friendship with patients, the risks are real. Patient/psychiatrist dyads very often lead in completely surprising and unanticipated directions, as the two get to know each other over time and, to use Aristotle's phrase, "eat salt together." Most experienced therapists, working with patients who have gotten well and remain in longterm treatment, realize that there is no way to control or regulate their feelings simply by making a conscious determination to function strictly in accordance with professional guidelines and regulations. Friendship ultimately is unavoidable in many cases. The question is not whether it will develop, but how it can be managed in a way that protects and enhances the life of the patient and, hopefully, the psychiatrist as well.

Patient/psychiatrist friendship, whether during or after the course of treatment, may never be a fully co-equal friendship. Even months or years after the termination of treatment, a strong argument could be made that the psychiatrist still has a more robust moral obligation to protect and serve the best interests of the former patient than the former patient does toward the psychiatrist. Again, as per Aristotle, this relative inequality does not mean the friendship cannot be "abiding and excellent" and thereby approach (or fully rise to) the essence of Aristotle's "perfect friendship." In fact, we may go a step beyond Aristotle to fashion an argument that no friendship is ever fully coequal, as the inherent differences between two individuals immediately and necessarily sets up a substantive inequality. One friend may be wealthier than another and thereby be in an empowered situation (or, conversely, be subject to jealousy and exploitation by the less moneyed friend). One friend may have a richer family or social life than the other, thereby establishing significant emotional needs and opportunities for each. One friend may develop a terminal illness while the other remains healthy, again setting up logistical and emotional factors that can make the friendship unequal at different times and in different ways. We no more want to say that such ordinary interpersonal situations detract from the possibility or reality of Aristotelian perfect friendship than the situation in which a psychiatrist and his or her former patient develop a relationship that transcends the usual professional structure.

The pragmatist viewpoint on this issue is that there is no absolute definition of friendship in general or in the patient/psychiatrist situation in particular. Being a friend to a patient may, for the psychiatrist, involve attending a graduation or wedding or other special life event; it may involve accepting a gift from a patient (or, in rare cases) giving a gift to a patient; it may (also in rare cases) involve "friending" a patient on Facebook or another online social networking site, a scenario and challenge I recently published a paper about in the Journal of Medical Ethics (2009). Most importantly for our current purposes, though, a patient/psychiatrist friendship may approach or fully develop into an Aristotelian perfect friendship between two essentially good, virtuous individuals. And the flowering of this friendship may actually represent, or at least be compatible with, the very best that psychiatric treatment has to offer. The pragmatist viewpoint further states that there should be no prima facie prohibitions on the development of these relationships, but that the development of such relationships should occur in the context of a careful consideration by the psychiatrist, the (current or former) patient, and perhaps others 
(including hospital administrators, professional societies, and licensing boards) of 8 factors which I will presently define.

In some of my past work (Brendel 2006), I have described the tension psychiatrists experience between working as scientists who aim to diagnose, categorize, and treat patients in accordance with "evidence-based" medicine, while at the same time working as humanists who deeply understand and work with each patient's unique interpersonal, emotional, and existential situation. Working within this tension is one of the great challenges and thrills of modern psychiatric practice, and in my book Healing Psychiatry, I delineated a pragmatic model for handling the tension between science and humanism. In this paper, I move on to address this other core tension and dilemma that psychiatrists face, which entails negotiating the obligations of the professional role and the critical importance of forging a human alliance and, perhaps, a friendship with the patient.

In Healing Psychiatry, I defined the "4 p's" of clinical pragmatism as the key factors in a conceptual and practical structure for good psychiatric practice. Those 4 p's involved the practical aspects of all psychiatric diagnosis and treatment; the pluralistic nature of the tools that psychiatrists use in diagnosing and treating complex, mental disorders; the participatory nature of diagnosis and treatment, with the patient sharing actively in decision making; and the provisional nature of diagnosis and treatment in psychiatry, given the complexity of the human mind and brain. These 4 p's of clinical pragmatism were rooted in the thinking of classical American pragmatists, including Charles Sanders Peirce (1904), William James (1909), and John Dewey (1929). They are also strongly influenced by the work of more contemporary pragmatic philosophers and bioethicists, such as Christopher Tollefsen (2000) and Glenn McGee (2003). For example, the falliblism of Peirce, the pluralism of James, and the participatory democratic attitude of Dewey all combine with their privileging of good practical results in many forms of life - and help to define a structure for the 4 p's.

These thinkers urge us to pay close attention to the practical applications of scientific study, the multiplicity of phenomena that render such study useful, the participation of many individuals in formulating collaborative and workable hypotheses, and the provisional nature of scientific understanding. Along these lines, pragmatism in modern-day psychiatry can be understood as a clinical sensibility and methodology that aims for favorable treatment outcomes for patients by respecting the practical, pluralistic, participatory, and provisional aspects of psychiatric explanation. Clinical pragmatism demands that psychiatrists have the skill and flexibility to employ multiple explanatory concepts (spanning the entire biopsychosocial spectrum) in an interactive and collaborative process with patients, which under most circumstances can lead to open-ended but useful clinical explanations and treatment plans. (Brendel 2006:s 5-6)

The subtitle of Healing Psychiatry is Bridging the Science/Humanism Divide. For the topic at hand in this paper, we might transmute that to Bridging the Regulation/Friendship Divide. In addressing the question of patient/psychiatrist friendship, I invoke the 4 p's from Healing Psychiatry and transform them for the current purpose, then add another 4 p's that also must be seriously considered in this context. Thus, the 8 p's constituting the pragmatist viewpoint on patient/psychiatrist friendship can be formulated as follows. Whenever a psychiatrist notices the incipient development of a friendship (widely considered) with a patient, he or she should think carefully about the following 8 questions:

Practicality: Our question cannot be solved on a purely theoretical or conceptual level, as emotion-driven, textured, real human relationships are not conducted on that plane. 
Consistent with the most basic tenet of philosophical pragmatism, we need to ask whether such relationships can work in the real world. As mentioned, psychiatrists may make a practical decision to attempt to avoid the development of an Aristotelian friendship within clinical practice, but such an attempt may fail and, if it succeeds, may rob the practice of an important human factor. That would be one crude form of pragmatist approach to the problem of patient/psychiatrist friendship. The deeper pragmatist point here, however, is that the conceptual question must be answered on the basis of practice rather than principles.

Pluralism: William James's work, ranging from his brilliant work A Pluralistic Universe to his Varieties of Religious Experience, embodies the great pragmatist point about the diversity and messiness of the universe - metaphysically, epistemologically, existentially, and ethically. Building on James's seminal work and its modern iterations in scholarship and cultural trends regarding pluralism, my view in the current context is that friendship takes many forms and can occur between many different types of people, notwithstanding superficial facts about people which might lead us to think that equal friendship in Aristolte's sense is not possible. Friendship between parent and child, professor and student, clergyman and congregant, physician and patient - all of these are possible for the pragmatist. Legislation, regulation, oversight, workplace rules cannot prevent their development.

Participation of Patient: In a non-hierarchical pragmatist world, neither psychiatrist nor patient is in a privileged position to decide on the nature of their relationship alone. Friendship is co-constructed between two autonomous adults acting as plural agents, in Helm's sense of the term. Neither party, and certainly not any outside third party, can decide alone whether to regard or call the relationship a friendship. The participatory approach is consistent with, and reinforces, the previous points about the practical and pluralistic nature of the question and the friendship relationship itself.

Provisionality: Friendships are not perfect and are not set in stone. Over the course of time, they transform themselves in unanticipated and unpredictable ways. Aristotle discusses an ideal "perfect friendship," but the pragmatist will probably part ways with him to say that friendships are fallible and ever changing. A patient/psychiatrist dyad may transform itself into a friendship between two people who used to work together professionally, and from there the friendship may grow and prosper, or it may fade and wither. The question of whether it can grow into more than a friendship - perhaps a romance or a business partnership - is more complicated because of the traditional ethics prohibitions in this area. The pragmatist does not rule out the possibility of such a transformation on theoretical grounds, but will look to some of the other 4 p's for guidance about whether and how this may be safe and practical.

Professionalism: The psychiatrist with an open-minded understanding of the practical, pluralistic, participatory, and provisional aspects of friendships - and a receptivity to the possibility of Aristotelian friendship growing out of a patient/doctor relationship - must be knowledgeable and reflective about the professional norms of the practice community of which he or she is a member. Rules about avoidance of exploitation of a vulnerable patient should be considered inviolable. But professionalism is more a habit of thinking and self-reflection than a set of clear and distinct rules in most of the situations we are considering today, in which there is no exploitation but the usual patient/doctor boundaries may become fuzzy as each individual autonomously chooses to get closer and engage in activities that are outside the usual professional bounds. 

that it is difficult - if not impossible - to guarantee that someone will never get hurt as the result of a friendship between a psychiatrist and a former patient. This fact is part of the provisionality of all such friendship. Some psychiatrists will choose to make an active point of avoiding such situations as much as they can. But when feelings begin to develop between the two parties, both of them (but especially the psychiatrist) must be careful to take protective steps. The psychiatrist must assure that the patient has another capable clinician looking after any and all treatment needs, for example. The psychiatrist also owes himself or herself a measure of self-protection - this may involve consulting with an attorney or ethics committee to discuss the propriety of the friendship, and documenting those discussions in writing in case of later legal or regulatory trouble.

Peer review: This last point regarding self-protection can be understood under the broader rubric of peer review. Here is where we may return to consider the plausibility of Habermas's notion of communicative rationality via discourse. Can a group of professional peers discuss the question about a particular patient/psychiatrist friendship in a safe, confidential, open-minded setting - and thereby come to a rational consensus about an appropriate course of action? And can other convened groups - such as a hospital ethics committee or a state medical board - discuss these questions in a rational discourse that leads to a consensus that rises to the level of truth, or at least normativity? The psychiatrist confronting the question of whether he or she can develop a friendship with a patient must consider and engage in some form of peer review, though such discussion forums are few and far between because of the fear and shame that surround the issue.

Privacy: Ultimately, the two individuals engaged in the friendship must decide on what they wish their relationship to be, and the pragmatist will allow them to make this work by respecting their autonomy and personhood. The question here is whether the medical profession or society more broadly should regulate this kind of relationship between a psychiatrist and a patient, in order to protect certain principles or tenets. For example, some hospital policies prohibit this kind of relationship, mainly to defend the hospital against possible future lawsuits or negative media attention. State regulators may choose to revoke a practitioner's license on the basis of such a friendship in order to protect the integrity and reputation of the medical profession. In the battle over privacy, the individual psychiatrist and the policy maker alike must grapple with the question of whether the individual person's privacy rights are greater or lesser than the interests of the medical profession and the state. The pragmatist does not have a ready-made position on this question, but believes that the tension must be grappled with in a fair, openminded, and non-dogmatic fashion.

\section{Conclusion}

There are more questions than answers about the feasibility of friendship between contemporary psychiatrists and those they serve in professional practice. Can patients and psychiatrists be friends? From a pragmatic standpoint, if they choose to make it work, then yes they can. A long-term psychiatric treatment relationship may, in fact, be a favorable breeding ground for Aristotelian perfect friendship and beyond. At the same time, we know that such friendship involves significant risk and may come at a high cost for patient and psychiatrist alike. We must ask ourselves whether such friendship really 
can work in light of the traditional, psychoanalytically based view of patient/doctor boundaries and all the rules, regulations, and forms of disciplinary action and shaming that arise around that notion of boundaries. William James once said that "wherever you are it is your friends who make your world." We know how important friendship, in all its manifestations, is for human flourishing. We have known that since Aristotle and well before him. What we do not yet know, in our technocratic and highly regulated medical world, is whether psychiatrists are to be barred from friendships with certain other autonomous human beings with whom they may develop very deep and meaningful relationships.

\section{BIBLIOGRAPHY}

ARISTOTLE, (1941), “Nicomachean Ethics," in McKeon R. (ed.), The Basic Works of Aristotle, New York, Random House.

DEWEY J., (1929), “The Quest for Certainty: A Study of the Relation of Knowledge and Action," in Boydston J. A., ed., The Later Works, Carbondale, IL, Southern Illinois University Press.

DEWEY J., (1934), Art as Experience, New York, Penguin Group.

BRENDEL D. H., (2006), Healing Psychiatry: Bridging the Science/Humanism Divide, Cambridge, MIT Press.

BRENDEl D. H., CHU J., RADDEN J., LEEPER H., POPE H.G., SAMSON J., TSIMPREA G. \& J. A. BODKIN, (2007), "The Price of a Gift: An Approach to Receiving Gifts from Patients in Psychiatric Practice," Harvard Review of Psychiatry, 15 (2), 43-51.

FOUCAUlT M., (1965), Madness and Civilization, New York, Random House.

Gabbard G. O. \& C. NADELSON, (1995), "Professional Boundaries in the Physician-Patient Relationship," Journal of the American Medical Association, 273 (18), 1445-9.

GUSEH J. S., BRENDEL R. W. \& D. H. BRENDEL, (2009), “Medical Professionalism in the Age of Online Social Networking," Journal of Medical Ethics, 35 (9), 584-6.

HABERMAS J., (1998), On the Pragmatics of Communication, Cambridge, MIT Press.

HARDIMON M. O., (1994), "Role Obligations," The Journal of Philosophy, 91 (7), 333-63.

HELM B. W., (2010), Love, Friendship \& the Self, Oxford, Oxford University Press.

JAMES W., (1909), A Pluralistic Universe, New York, Longmans, Green.

MCGEE G. (ed.), (2003), Pragmatic Bioethics, 2nd edition, Cambridge, MIT Press.

PEIRCE C. S., (1904), “A Definition of Pragmatism," in Menand L. (ed.), Pragmatism: A Reader, New York, Vintage Book.

RORTY R., (1982), Consequences of Pragmatism, Minneapolis, University of Minnesota Press.

tollefsen C., (2000), "What Would John Dewey Do?: The Promises and Perils of Pragmatic

Bioethics," Journal of Medicine and Philosophy 25, 77-106. 
WERTHEIMER A., (1999), Exploitation, Princeton, Princeton University Press

\section{ABSTRACTS}

Relationships between patients and psychiatrists are shaped by a complex array of factors. The clinical experience centers on diagnostic and treatment decisions occurring in the context of a structured relationship that is regulated by principles of professional ethics and personal boundaries. At the same, however, patients and psychiatrists are unique and autonomous agents with emotional responses to one another that may evoke a wish for a personal friendship or other sorts of personal relationships that are outside the bounds of the usual professionally defined structures. Negotiating the tension between the need for professional regulation and the desire for developing a friendship with certain patients can present clinical and ethical challenges in psychiatric practice. Pragmatist reasoning can help the psychiatrist and patient to successfully negotiate the dilemma that may arise when either or both of them wishes to develop a personal friendship but still adhere to the ethical tenets of the patient/psychiatrist professional dyad.

\section{AUTHOR}

DAVID H. BRENDEL

David[at]drdavidbrendel.com 